\title{
Short communication: Influence of the muscle hypertrophy mutation of the myostatin gene on milk production traits and milk fatty acid composition in dual-purpose Belgian Blue dairy cattle
}

\author{
B. Buske, ${ }^{*}$ N. Gengler, ${ }^{,} \dagger^{1}$ and H. Soyeurt ${ }^{\star} \dagger$ \\ *Animal Science Unit, Gembloux Agro-Bio Tech, University of Liège, B-5030 Gembloux, Belgium \\ †National Fund for Scientific Research, B-1000 Brussels, Belgium
}

ABSTRACT

The objective of this study was to estimate genetic effects for the muscle hypertrophy mutation (mh) of the myostatin gene for conventional milk production traits and for milk fatty acid composition in dual-purpose Belgian Blue dairy cows. For the present study, only cows from a single herd, in which genotype frequencies were as balanced as possible $(0.266$ for $+/+, 0.523$ for $\mathrm{mh} /+$, and 0.211 for $\mathrm{mh} / \mathrm{mh}$ ), were chosen to avoid confounding between herd and genotype effects. A total of 109 cows with 3,190 test-day records for fat, protein, and milk yields and 1,064 test-day records for saturated and monounsaturated fatty acids were used for the calculations. Variance component and gene effect estimations were performed via expectation-maximization REML and BLUP methods, respectively, using a multitrait mixed test-day model with an additional fixed regression on the muscle hypertrophy genotype. Results showed that one copy of the wild-type "+" allele led to a significant additive effect of $26.35 \mathrm{~g} / \mathrm{d}$ for fat yield. Significant dominance effects of $23.22 \mathrm{~g} / \mathrm{d}$ for protein yield and $30.28 \mathrm{~g} / \mathrm{d}$ for fat yield were also observed. In contrast, a nonsignificant trend was observed in favor of lower saturated fatty acid contents in milk for one copy of the mutant "mh" allele. Concerning milk, fat, and protein yields, our results confirmed literature results indicating a superior effect of the "+" allele compared with the mutant allele. Therefore, the selection of the "+" allele has the potential to increase conventional milk production traits in the dual-purpose Belgian Blue breed. However, when focus is given to milk fatty acid profile, a possible antagonistic effect between the benefit of the "+" allele for higher milk production and the "mh" allele for reduced saturated fatty acid content in milk should be confirmed in further studies.

Key words: candidate gene, fatty acid composition, milk production, myostatin

Received December 3, 2010

Accepted March 16, 2011.

${ }^{1}$ Corresponding author: nicolas.gengler@ulg.ac.be

\section{Short Communication}

In recent years, milk fat composition in technologically developed countries has become of high interest because of specific consumer demands in addition to the classical production traits milk, protein, and fat yields, and protein and fat percentages. Increases in unsaturated fatty acids at the expense of saturated fatty acids are considered favorable because of technical properties (e.g., spreadability of butter) and human health aspects. Recently, a new and inexpensive method using mid-infrared spectrometry to quantify those fatty acids in milk was developed (e.g., Soyeurt et al., 2006, 2011), which is useful for routine analyses. At least for saturated fatty acids (SFA) and monounsaturated fatty acids (MUFA), this methodology leads to reliable quantification and could therefore be implemented into routine evaluation of cattle breeding values. Furthermore, it has been shown that genetic variability for fatty acids exists in cattle (Soyeurt et al., 2008; Stoop et al., 2008).

The dual-purpose Belgian Blue (DP-BB) breed is a local dual-purpose (beef and milk) strain of the Belgian Blue breed. Breeders of DP-BB make their selection decisions on the basis of the muscle hypertrophy mutation of the myostatin $(\boldsymbol{M S T N})$ gene. Several recent studies (e.g., Buske et al., 2010, 2011) showed that the wild-type "+" allele of this gene is responsible for moderately higher milk, protein, and fat yields in DP-BB cows. It is also known that meat composition for fatty acids of Belgian Blue animals seems to be affected by muscle hypertrophy genotypes (Raes et al., 2001). Recently, these findings were confirmed in the British South Devon cattle breed (Wiener et al., 2009). Both studies found significant reductions for SFA and an increase of the ratio of polyunsaturated fatty acids to SFA for the mutant "mh" allele. Thus, the muscle hypertrophy mutation could also have a major effect on milk fatty acid composition. One objective of this study was therefore to investigate whether the muscle hypertrophy mutation is also involved in the production of SFA and MUFA in cow's milk. 
However, estimating additive and dominance effects of single mutations for desirable traits is generally difficult for several reasons. First, only a small part of a complete, often heterogeneous population is genotyped, which makes it difficult to estimate reliably such single mutation effects. To enlarge the genotyped sample, an estimation of the genotype based on additive relationships between genotyped and their nongenotyped relatives is an interesting alternative (Gengler et al., 2008), but a reliable estimation of the gene content is often not feasible (e.g., when the classical pedigree is highly incomplete and no information on linked genes is available). Another problem is the occurrence of confounding between herd and genotype effects, because some genotypes are concentrated in specific herds. For DPBB herds, it is difficult to separate these 2 effects because pre-examinations of field data showed that nearly all large herds consist of only 2 types of genotyped cows with a strong bias in favor of one homozygous genotype. This is due to different selection strategies of farmers, where some prefer animals carrying mutant "mh" alleles to increase their meat production, whereas others prefer cows carrying wild-type "+" alleles to increase their milk production. The occurrence of only 2 genotypes with a strong bias in favor of one homozygote is a common phenomenon in all kinds of populations under selection (Bagnicka et al., 2007) when these genes are directly involved, or at least linked to genes with major effects. Consequently, additive and dominance effects are unreliable or even not estimable.

To overcome this problem, we intended to investigate additive and dominance effects of the MSTN muscle hypertrophy mutation for milk performance traits including 2 new available fatty acid traits (SFA and MUFA) in the largest DP-BB purebred cow herd of the Walloon Region of Belgium, in which genotype frequencies were as balanced as possible.

In total, 109 genotyped DP-BB cows, with 3,190 testday (TD) records for milk, protein, and fat yields and 1,064 TD records for SFA and MUFA, were used for calculations. Cows came from only one herd to avoid confounding between herd and genotype effects. Test-day records for milk production traits were available since 2004 and those for fatty acids since 2007. All cows were genotyped for the muscle hypertrophy mutation of the MSTN gene using a method adapted from Fahrenkrug et al. (1999). The sequence of the mutant "mh" allele consists of a 11-bp deletion c.[819_829del] that causes a frameshift and premature translational termination and is therefore the underlying mutation for muscle hypertrophy (Fahrenkrug et al., 1999). Genotype and allele frequencies were $0.266(+/+), 0.523(\mathrm{mh} /+)$, and $0.211(\mathrm{mh} / \mathrm{mh})$ as well as $0.53(+)$ and $0.47(\mathrm{mh})$, respectively. Genotype frequencies were almost the same as the expected frequencies under Hardy-Weinberg equilibrium $(0.278,0.499$, and 0.223$)$, which supports the choice of this herd. Descriptive statistics for phenotypic records as well as the genotype distribution for the investigated cows are given in Table 1.

The number of lactations for cows varied between 1 and 10, and the number of TD records per lactation varied between 1 and 12 . Test-day records within the first $5 \mathrm{~d}$ after calving and after $365 \mathrm{~d}$ in milk were excluded from the data set. The pedigree for these 109

Table 1. Descriptive statistics for 109 cows in one herd sorted by the myostatin muscle hypertrophy genotype ${ }^{1}$

\begin{tabular}{|c|c|c|c|c|c|}
\hline $\begin{array}{l}\text { Genotype } \\
\text { and trait }\end{array}$ & $\mathrm{n}^{3}$ & Mean & SD & Minimum & Maximum \\
\hline \multicolumn{6}{|l|}{$+/+$} \\
\hline Milk (kg/d) & 797 & 16.10 & 6.00 & 3.20 & 42.60 \\
\hline Protein $(\mathrm{g} / \mathrm{d})$ & 797 & 522.1 & 168.06 & 120.1 & $1,427.1$ \\
\hline Fat $(g / d)$ & 797 & 575.3 & 220.63 & 104.0 & $1,713.0$ \\
\hline SFA & 253 & 2.471 & 0.470 & 0.477 & 3.931 \\
\hline MUFA & 253 & 1.037 & 0.285 & 0.376 & 2.511 \\
\hline \multicolumn{6}{|l|}{$+/ \mathrm{mh}$} \\
\hline Milk (kg/d) & 1,741 & 16.65 & 6.06 & 3.10 & 39.20 \\
\hline Protein $(g / d)$ & 1,741 & 543.6 & 173.57 & 124.6 & $1,153.4$ \\
\hline Fat $(\mathrm{g} / \mathrm{d})$ & 1,741 & 603.0 & 226.29 & 105.6 & $1,778.9$ \\
\hline SFA & 610 & 2.532 & 0.418 & 0.973 & 3.830 \\
\hline MUFA & 610 & 1.018 & 0.270 & 0.382 & 2.059 \\
\hline \multicolumn{6}{|l|}{$\mathrm{mh} / \mathrm{mh}$} \\
\hline Milk (kg/d) & 652 & 16.00 & 5.48 & 3.30 & 31.90 \\
\hline Protein (g/d) & 652 & 508.2 & 151.76 & 144.5 & 976.5 \\
\hline Fat $(\mathrm{g} / \mathrm{d})$ & 652 & 541.1 & 178.45 & 69.3 & $1,258.6$ \\
\hline SFA & 201 & 2.355 & 0.437 & 1.559 & 3.746 \\
\hline MUFA & 201 & 1.026 & 0.261 & 0.564 & 2.016 \\
\hline
\end{tabular}

${ }^{1}$ Where $+=$ wild-type and $\mathrm{mh}=$ muscle hypertrophy mutation.

${ }^{2}$ Saturated fatty acids (SFA) and monounsaturated fatty acids (MUFA) are given in $\mathrm{g} / \mathrm{dL}$ of milk per test day.

${ }^{3}$ Additional historical data were included into the data set for milk, protein, and fat. 
genotyped cows was almost complete (i.e., $97.25 \%$ of genotyped cows with both known parents) and consisted of 620 animals, including genotyped cows and their nongenotyped ancestors. This final pedigree was extracted from the total pedigree, which is permanently updated and used for the official Walloon genetic evaluations (Croquet et al., 2006).

Variance components were newly estimated because we included the muscle hypertrophy mutation effect in addition to the classical polygenic effect in the model. Our intention was thereby to consider also the polygenic effect of all related animals, which is feasible with relatively small data sets (Bagnicka et al., 2007). To estimate variance components, a multi-trait mixed test-day model with an additional fixed regression on the MSTN muscle hypertrophy genotype was used. One multi-trait model with $n$ evaluated traits was preferred to $n$ single-trait models to exploit the availability of additional data for milk, protein, and fat yields. Moreover, correlations among traits could be used. The applied simple model was

$$
\mathbf{y}=\mathbf{X} \boldsymbol{\beta}+\mathbf{T d}+\mathbf{W} \mathbf{i}+\mathbf{Z u}+\mathbf{Z}^{*} \mathbf{p}+\mathbf{Z}^{*} \mathbf{Q g}+\mathbf{e},
$$

where $\mathbf{y}$ is a vector of TD records representing the phenotype of the animal, $\boldsymbol{\beta}$ is a vector of fixed effects, $\boldsymbol{d}$ is a vector for a random TD effect, $\mathbf{i}$ is a vector for a random permanent environment intra-lactation effect, $\mathbf{p}$ is a vector for a random permanent environment inter-lactation effect, and e represents the residual. The vector $\mathbf{u}$ represents the random polygenic animal effect, with $\operatorname{Var}(\mathbf{u})=\mathbf{A} \sigma_{u}^{2}$, where $\mathbf{A}$ is the numerator relationship matrix and $\sigma_{u}^{2}$ the polygenic additive variance, and g represents the fixed $M S T N$ muscle hypertrophy genotype effects including an additive effect $(a)$ defined as the estimated value for one copy of the "+" allele (i.e., an allele substitution effect) and a dominance effect (d) defined as the estimated value for the deviation of the heterozygous genotype from the mean of both homozygous genotypes. The incidence matrices $\mathbf{X}, \mathbf{T}, \mathbf{W}$, and $\mathbf{Z}$ link the records to the fixed effects, test-day, animal $\times$ lactation number, and animals, respectively, whereas $\mathbf{Q}$ is a matrix linking animals to their muscle hypertrophy genotype. Elements of $\mathbf{Q}$ were set to 1,0 , and -1 (additive effect) and to 0,1 , and 0 (dominance effect) for the $+/+, \mathrm{mh} /+$, and $\mathrm{mh} / \mathrm{mh}$ genotypes, respectively. The matrix $\mathbf{Z}^{*}$ represents the nonzero part of $\mathbf{Z}$.

The following 5 traits were considered: milk, protein, and fat yields (kg/TD) and SFA and MUFA (both in $\mathrm{g} / \mathrm{dL}$ of milk). Observations for these fatty acids were calculated from mid-infrared spectral data. Briefly, each milk sample was analyzed by the Milk Committee (Comité du Lait, Battice, Belgium) using a
MilkoScan FT6000 spectrometer (Foss, Hillerød, Denmark). Thereafter, fatty acid contents were calculated using calibration equations developed by Soyeurt et al. (2011).

Apart from the genotype effect, further fixed effects were the combination between lactation class (3 levels) and lactation stage (19 levels), the season in month (11 levels due to no performed recording in July), and the year of sampling (6 levels). Concerning lactation class, third and later lactation numbers were combined. For simplicity and due to data limitation, variance components for all random effects were assumed homogeneous and uncorrelated, which is not, strictly speaking, the case for single mutation and polygenic effects. However, for calculation ease, possible covariances between these 2 effects were ignored. Variance component estimation was performed with the expectation-maximization REML procedure simultaneously using all 3,190 TD records for milk, protein, and fat yield and 1,064 TD records for the fatty acids. This is the method of choice when calculation time is unimportant or fast (e.g., due to a small data set) and conditions about starting values are fulfilled (Misztal, 2008). Starting values for variances for each random effect were the phenotypic variance of each trait. Thus, they were generally higher than the estimated ones, which is strongly recommended by Misztal (2008) and Tsuruta et al. (2004). Starting values for covariances between any different traits $a$ and $b$ were calculated as

$$
|C O V|=\sqrt{\operatorname{Var}(a) \times \operatorname{Var}(b)} .
$$

Mean TD heritabilities $\left(h^{2}\right)$ were calculated as $h^{2}=\sigma_{u}^{2} / \sigma_{T}^{2}$, where $\sigma_{u}^{2}$ is the polygenic additive variance and $\sigma_{T}^{2}$ is the total variance, which is a summation of all variance components.

Estimation of additive and dominance $M S T N$ muscle hypertrophy genotype effects was performed using the BLUP procedure with the same model applied for the variance component estimation. Variance components were the newly estimated ones as described above. The equations for the BLUP were solved directly using a modified sparse-inversion BLUP program (Misztal et al., 2002) because the data set and the corresponding pedigree file were small. Using this approach has the advantage that the inverse elements of the coefficient matrix $\mathbf{C}$ can be obtained directly. According to Henderson (1975), standard errors for the fixed effects are the square root of the corresponding diagonal elements of that inverse, which were provided by the aforementioned program. Therefore, significance of additive allele substitution and dominance effects could be tested 
Table 2. Estimated variance components ${ }^{1}$ using expectation maximization-REML ${ }^{2}$

\begin{tabular}{|c|c|c|c|c|c|c|}
\hline Effect & $\begin{array}{l}\text { Level }^{3} \\
\text { (n) }\end{array}$ & $\begin{array}{c}\mathrm{Milk}^{2} \\
(\mathrm{~kg} / \mathrm{d})\end{array}$ & $\begin{array}{c}\text { Protein }^{2} \\
(\mathrm{~g} / \mathrm{d})\end{array}$ & $\begin{array}{l}\mathrm{Fat}^{2} \\
(\mathrm{~g} / \mathrm{d})\end{array}$ & $\begin{array}{c}\mathrm{SFA}^{2} \\
(\mathrm{~g} / \mathrm{dL})\end{array}$ & $\begin{array}{c}\text { MUFA }^{2} \\
(\mathrm{~g} / \mathrm{dL})\end{array}$ \\
\hline Test day & 71 & 0.3992 & 721.4 & 750.4 & 1.627 & 0.1847 \\
\hline Permanent environment ${ }_{1 \text { (intra lact) }}$ & 402 & 2.578 & 2,267 & 3,436 & 0.5028 & 0.1118 \\
\hline Animal & 620 & 1.263 & 1,030 & 1,648 & 4.498 & 0.2122 \\
\hline Myostatin additive & 3 & - & - & - & - & - \\
\hline Myostatin dominance & 2 & - & - & - & - & - \\
\hline
\end{tabular}

${ }^{1}$ Variances for saturated fatty acids (SFA) and monounsaturated fatty acids (MUFA) are multiplied by 100.

${ }^{2}$ Starting values for variances for each effect were the phenotypic variances; starting values for covariances were calculated as $\mid$ Cov $\mid=\operatorname{sqrt}[$ Var(a) $\times \operatorname{Var}(\mathrm{b})]$.

${ }^{3}$ Test day (71 levels), year of control (6 levels), and month of control (11 levels) as fixed effects are not presented in the table.

using a 2-tailed Student's $t$-test. The value $\mathrm{t}_{\mathrm{obs}}$ for each effect was calculated as

$$
\mathrm{t}_{\mathrm{obs}}=\frac{\hat{\beta}}{\sqrt{\mathbf{C}^{\hat{\beta} \hat{\beta}}}},
$$

where $\hat{\beta}$ is the estimated fixed MSTN muscle hypertrophy genotype effect (additive or dominance) and $\mathbf{C}^{\hat{\beta} \hat{\beta}}$ is the corresponding diagonal element. The corresponding degrees of freedom were calculated by $\mathrm{N}-\operatorname{rank}(\mathbf{X})$, where $\mathrm{N}$ is the number of TD records and $\mathbf{X}$ is the matrix as described previously.

Concerning variance component estimation using the applied multi-trait approach with 5 traits evaluated simultaneously, convergence $\left(<1.0 \mathrm{e}^{-10}\right)$ was reached without difficulty after approximately 1,270 rounds. Results showed that, in contrast to the conventional milk production traits (milk, protein, and fat yield), the test-day variance for both fatty acids was higher than the variances for intra- and inter-lactation variances (Table 2), indicating that the test-day plays an important role in fatty acid variability. Test-day heritabilities for milk (0.124), protein (0.098), and fat (0.089) yields were low and similar for these 3 traits (Table 3 ). The similarity among these traits was expected because they are phenotypically highly correlated (Table 3). By contrast, heritability for SFA was quite high
(0.321) whereas the heritability for MUFA (0.064) was very low. This difference was also observed in a study from Soyeurt et al. (2008), although their values were higher for SFA (0.42) and MUFA (0.14), indicating that MUFA generally seem to be less genetically determined in contrast to SFA.

Neither a significant additive nor dominance $M S T N$ muscle hypertrophy genotype effect was observed on any fatty acid group. This was expected because descriptive statistics (Table 1) showed relatively high standard deviations by only slight mean phenotypic differences for the 3 genotypes. Only a nonsignificant trend in favor of decreased SFA content in milk for the "mh" allele was observed. Concerning additive effects, one copy of the "+" allele led to increases on milk, protein, and fat yields, the latter being significant (Table 4). These results are in good agreement with earlier studies (Buske et al., 2010, 2011). In the current study, important dominance effects were also observed for milk, fat, and protein yields, which were significant for fat and protein yields. Moreover, dominance effects were even higher than additive effects, which is generally a rare observation. However, to a slightly lower extent, dominance effects for milk, fat, and protein yields were observed by Buske et al. (2010), using the complete genotyped DP-BB cow population of the Walloon Region of Belgium, which is distributed over 72 herds. This difference might be explained by the

Table 3. Averaged test-day heritabilities (diagonal) and genetic (above) and phenotypic (below) correlations among studied traits ${ }^{1}$

\begin{tabular}{lccccc}
\hline Trait & $\begin{array}{c}\text { Milk } \\
(\mathrm{kg} / \mathrm{d})\end{array}$ & $\begin{array}{c}\text { Protein } \\
(\mathrm{g} / \mathrm{d})\end{array}$ & $\begin{array}{c}\text { Fat } \\
(\mathrm{g} / \mathrm{d})\end{array}$ & $\begin{array}{c}\text { SFA } \\
(\mathrm{g} / \mathrm{dL} \text { of milk })\end{array}$ & $\begin{array}{c}\text { MUFA } \\
(\mathrm{g} / \mathrm{dL} \text { of milk })\end{array}$ \\
\hline Milk & $\mathbf{0 . 1 2 4}$ & 0.787 & 0.436 & -0.4712 & 0.036 \\
Protein & 0.966 & $\mathbf{0 . 0 9 8}$ & 0.832 & 0.037 & 0.622 \\
Fat & 0.908 & 0.917 & $\mathbf{0 . 0 8 9}$ & 0.566 & 0.704 \\
SFA & -0.058 & 0.034 & 0.263 & $\mathbf{0 . 3 2 1}$ & 0.512 \\
MUFA & -0.391 & -0.363 & -0.211 & -0.034 & $\mathbf{0 . 0 6 4}$ \\
\hline
\end{tabular}

${ }^{1}$ Myostatin muscle hypertrophy genotype was treated as a fixed effect. SFA = saturated fatty acids, MUFA = monounsaturated fatty acids. 
Table 4. Additive $^{1}$ and dominance test-day effects (SE in parentheses) of the myostatin muscle hypertrophy mutation for milk performance traits and saturated (SFA) and monounsaturated (MUFA) fatty acids

\begin{tabular}{lccccc}
\hline Effect & $\begin{array}{c}\text { Milk } \\
(\mathrm{kg})\end{array}$ & $\begin{array}{c}\text { Protein } \\
(\mathrm{g})\end{array}$ & $\begin{array}{c}\text { Fat } \\
(\mathrm{g})\end{array}$ & $\begin{array}{c}\text { SFA } \\
(\mathrm{g} / \mathrm{dL} \text { of milk })\end{array}$ & $\begin{array}{c}\text { MUFA } \\
(\mathrm{g} / \mathrm{dL} \text { of milk })\end{array}$ \\
\hline Myostatin ${ }_{\text {additive }}$ & 0.466 & 15.44 & $26.35^{*}$ & 0.0489 & -0.0084 \\
& $(0.290)$ & $(8.700)$ & $(10.526)$ & $(0.031)$ & $(0.010)$ \\
Myostatin $_{\text {dominance }}$ & 0.565 & $23.22^{*}$ & $30.28^{*}$ & 0.0296 & -0.0126 \\
& $(0.385)$ & $(11.563)$ & $(13.936)$ & $(0.039)$ & $(0.014)$ \\
\hline
\end{tabular}

${ }^{1}$ Allele substitution effect for 1 copy of the wild-type "+" allele.

${ }^{*} P<0.05$ using a 2-tailed Student's $t$-test.

fact that in the currently evaluated herd, heterozygote cows performed slightly better than homozygous $+/+$ cows (Table 1), which is not the case for the complete genotyped cow population (data not shown). Therefore, to extend our results to the complete local population, further herds with sufficiently balanced genotype frequencies should be included to improve the prediction of genotype effects. However, in the current study, none of the remaining large herds fulfilled such requirements.

Besides numerous association studies between candidate genes and milk production traits, studies have also reported on associations between candidate genes and milk fat composition. Schennink et al. (2008), for example, found significant effects for the A293V SNP of the stearoyl CoA desaturase gene on the fatty acid profile in cow's milk. In a further study, at least 25 associations between 7 SNP from 5 different genes in a (mainly Holstein) cow population and several fatty acids were observed (Schennink et al., 2009). However, these authors conclude that some of their associations could have been obtained just by chance simply because multiple tests were performed. Additionally, these SNP cannot be considered as causative mutations, and the results need to be confirmed before using them for breeding programs. Another important aspect is the consideration of antagonistic effects. Macciotta et al. (2008) found antagonistic effects between milk and protein yields on the one side and MUFA and desaturase activity on the other side for the A293V SNP in the stearoyl CoA desaturase gene. Depending on the breeding goal, such antagonistic effects have to be considered before implementing certain genes into breeding programs.

Concerning milk, fat, and protein yields, our results confirmed literature results for the benefit of the "+" allele. Therefore, the selection of the "+" allele can be an option to increase the conventional milk production traits in the DP-BB breed. However, when focus is given to milk fatty acid profile, a possible antagonistic effect between the benefit of the "+" allele for higher milk production and the "mh" allele for decrease SFA content in milk should be confirmed in further stud- ies. To improve the estimation of genotype effects, such studies should preferentially include several large herds with sufficiently balanced genotype frequencies to extend limited results to a complete local population.

\section{ACKNOWLEDGMENTS}

This research received financial support from the European Commission, Directorate-General for Agriculture and Rural Development, under Grant Agreement 211708 and from the Commission of the European Communities, FP7, KBBE-2007-1. This paper does not necessarily reflect the view of these institutions and in no way anticipates the Commission's future policy in this area. The authors gratefully also acknowledge the financial support of the Walloon Region of Belgium (projects D31-1224/S1 and D31-1168). Nicolas Gengler and Hélène Soyeurt, who are research associate and postdoctoral researcher, respectively, acknowledge their support from the National Fund for Scientific Research (Brussels, Belgium). The authors acknowledge the technical support provided by the Walloon Breeding Association (Ciney, Belgium) and thank S. Depoterre, University of Liège, for reviewing the manuscript.

\section{REFERENCES}

Bagnicka, E., N. Strzalkowska, K. Flisikowski, T. Szreder, A. Jóźwik, B. Prusak, J. Krzyzewski, and L. Zwierzchowski. 2007. The polymorphism in the $\beta 4$-defensin gene and its association with production and somatic cell count in Holstein-Friesian cows. J. Anim. Breed. Genet. 124:150-156.

Buske, B., M. Szydlowski, and N. Gengler. 2010. A robust method for simultaneous estimation of single gene and polygenic effects in dairy cows using externally estimated breeding values as prior information. J. Anim. Breed. Genet. 127:272-279.

Buske, B., M. Szydlowski, C. Verkenne, and N. Gengler. 2011. Estimating myostatin gene effect on milk performance traits using estimated gene content for a large number of non-genotyped cows. Animal 5:43-47.

Croquet, C., P. Mayeres, A. Gillon, S. Vanderick, and N. Gengler. 2006. Inbreeding depression for global and partial economic indexes, production, type, and functional traits. J. Dairy Sci. 89:2257-2267.

Fahrenkrug, S. C., E. Casas, J. W. Keele, and T. P. Smith. 1999. Technical note: Direct genotyping of the double-muscling locus $(\mathrm{mh})$ in Piedmontese and Belgian Blue cattle by fluorescent PCR. J. Anim. Sci. 77:2028-2030. 
Gengler, N., S. Abras, C. Verkenne, S. Vanderick, M. Szydlowski, and R. Renaville. 2008. Accuracy of prediction of gene content in large animal populations and its use for candidate gene detection and genetic evaluation. J. Dairy Sci. 91:1652-1659.

Henderson, C. R. 1975. Best linear unbiased estimation and prediction under a selection model. Biometrics 31:423-447.

Macciotta, N. P. P., M. Mele, G. Conte, A. Serra, M. Cassandro, R. Dal Zotto, A. Cappio Borlino, G. Pagnacco, and P. Secchiari. 2008. Association between a polymorphism at the stearoyl CoA desaturase locus and milk production traits in Italian Holsteins. J. Dairy Sci. 91:3184-3189.

Misztal, I. 2008. Reliable computing in estimation of variance components. J. Anim. Breed. Genet. 125:363-370.

Misztal, I., S. Tsuruta, T. Strabel, B. Auvray, T. Druet, and D. H. Lee. 2002. BLUPF90 and related programs (BGF90). CD-ROM Commun. 28-07 in Proc. 7th World Congr. Genet. Appl. Livest. Prod., Montpellier, France.

Raes, K., S. de Smet, and D. Demeyer. 2001. Effect of double-muscling in Belgian Blue young bulls on the intramuscular fatty acid composition with emphasis on conjugated linoleic acid and polyunsaturated fatty acids. Anim. Sci. 73:253-260.

Schennink, A., H. Bovenhuis, K. M. Léon-Kloosterziel, J. A. M. van Arendonk, and M. H. P. W. Visker. 2009. Effect of polymorphisms in the FASN, OLR1, PPARGC1A, PRL and STAT5A genes on bovine milk-fat composition. Anim. Genet. 40:909-916.

Schennink, A., J. M. L. Heck, H. Bovenhuis, M. H. P. W. Visker, H. J. F. Van Valenberg, and J. A. M. van Arendonk. 2008. Milk fatty acid unsaturation: Genetic parameters and effects of stearoyl-CoA desaturase (SCD1) and acyl CoA:diacylglycerol acyltransferase 1 (DGAT1). J. Dairy Sci. 91:2135-2143.

Soyeurt, H., P. Dardenne, F. Dehareng, C. Bastin, and N. Gengler. 2008. Genetic parameters of saturated and monounsaturated fatty acid content and the ratio of saturated to unsaturated fatty acids in bovine milk. J. Dairy Sci. 91:3611-3626.

Soyeurt, H., P. Dardenne, F. Dehareng, G. Lognay, D. Veselko, M. Marlier, C. Bertozzi, P. Mayeres, and N. Gengler. 2006. Estimating fatty acid content in cow milk using mid-infrared spectrometry. J. Dairy Sci. 89:3690-3695.

Soyeurt, H., F. Dehareng, N. Gengler, S. McParland, E. Wall, D. P. Berry, M. Coffey, and P. Dardenne. 2011. Mid-infrared prediction of bovine milk fatty acids across multiple breeds, production systems and countries. J. Dairy Sci. 93:1657-1667.

Stoop, W. M., J. A. M. van Arendonk, J. M. L. Heck, H. J. F. van Valenberg, and H. Bovenhuis. 2008. Genetic parameters for major milk fatty acids and milk production traits of Dutch Holstein Friesians. J. Dairy Sci. 91:385-394.

Tsuruta, S., I. Misztal, T. J. Lawlor, and L. Klei. 2004. Modelling final scores in US Holsteins as a function of year of classification using a random regression model. Livest. Prod. Sci. 91:199-207.

Wiener, P., J. A. Woolliams, A. Frank-Lawale, M. Ryan, R. I. Richardson, G. R. Nute, J. D. Wood, D. Homer, and J. L. Williams. 2009. The effects of a mutation in the myostatin gene on meat and carcass quality. Meat Sci. 83:127-134. 